\title{
Author Correction: Adherence to public institutions that foster cooperation
}

Arunas L. Radzvilavicius, Taylor A. Kessinger \& Joshua B. Plotkin (1)

Correction to: Nature Communications https://doi.org/10.1038/s41467-021-23783-9

The original version of this Article contained an error in Fig 2., in which for the left-most items in the "simple standing" and "shunning" rows, the top vertices were inadvertently displayed as filled blue circles where they should have been displayed as empty circles. 
The correct version of Fig. 2 is:

no institution
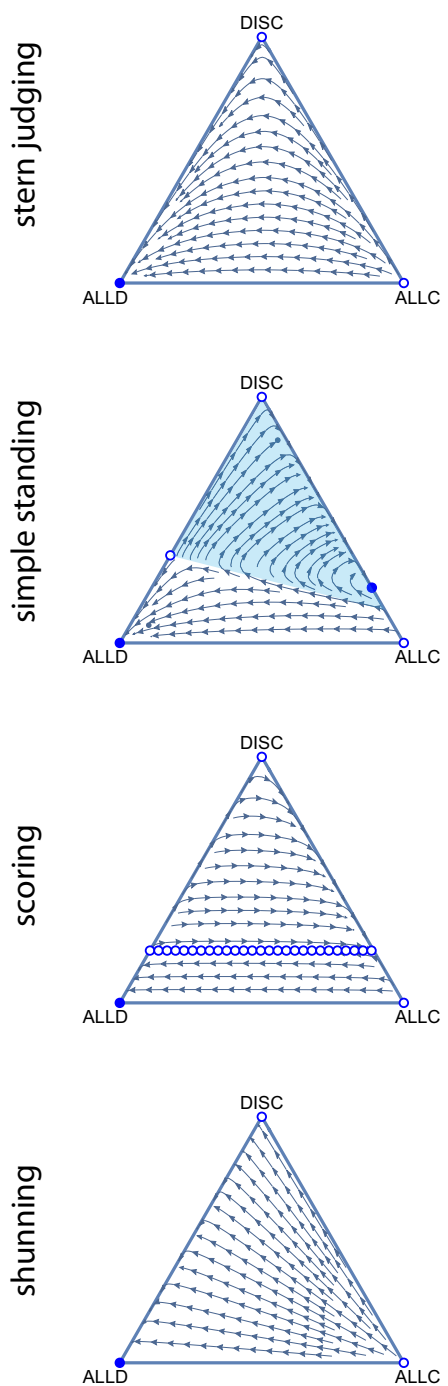

tolerant institution
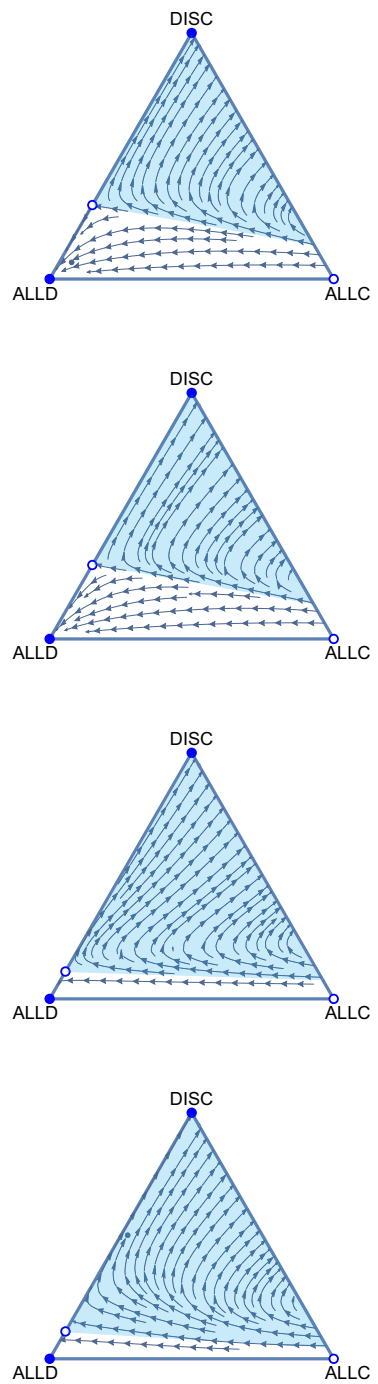
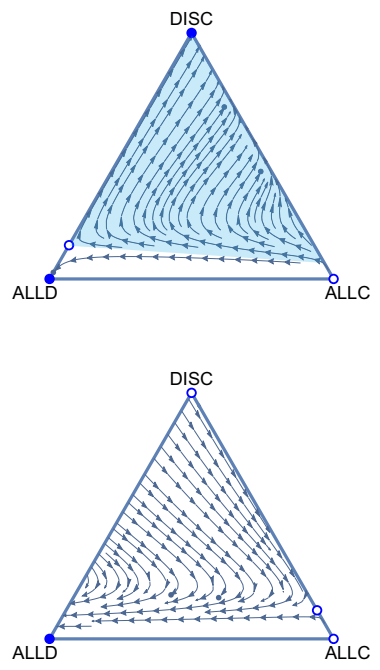

strict institution
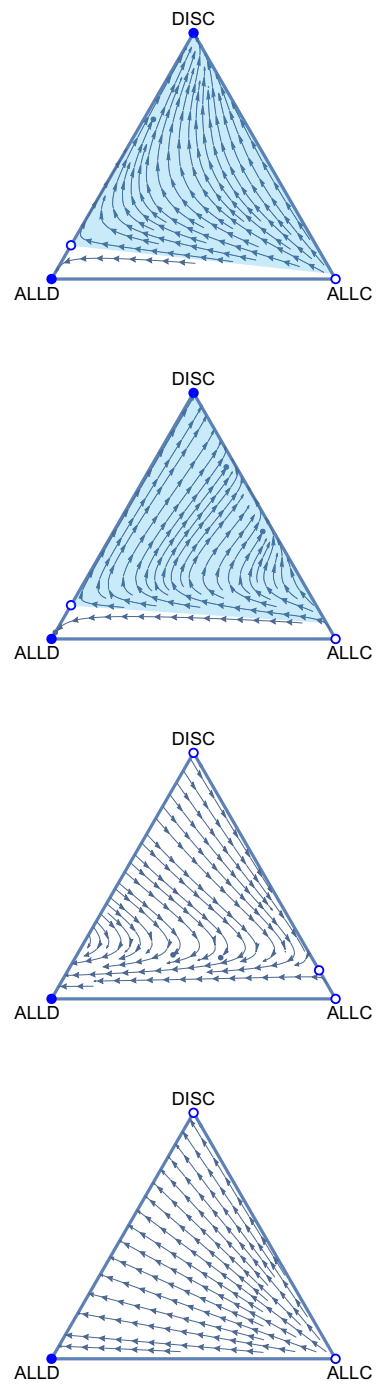
which replaces the previous incorrect version: no institution

\section{tolerant institution}
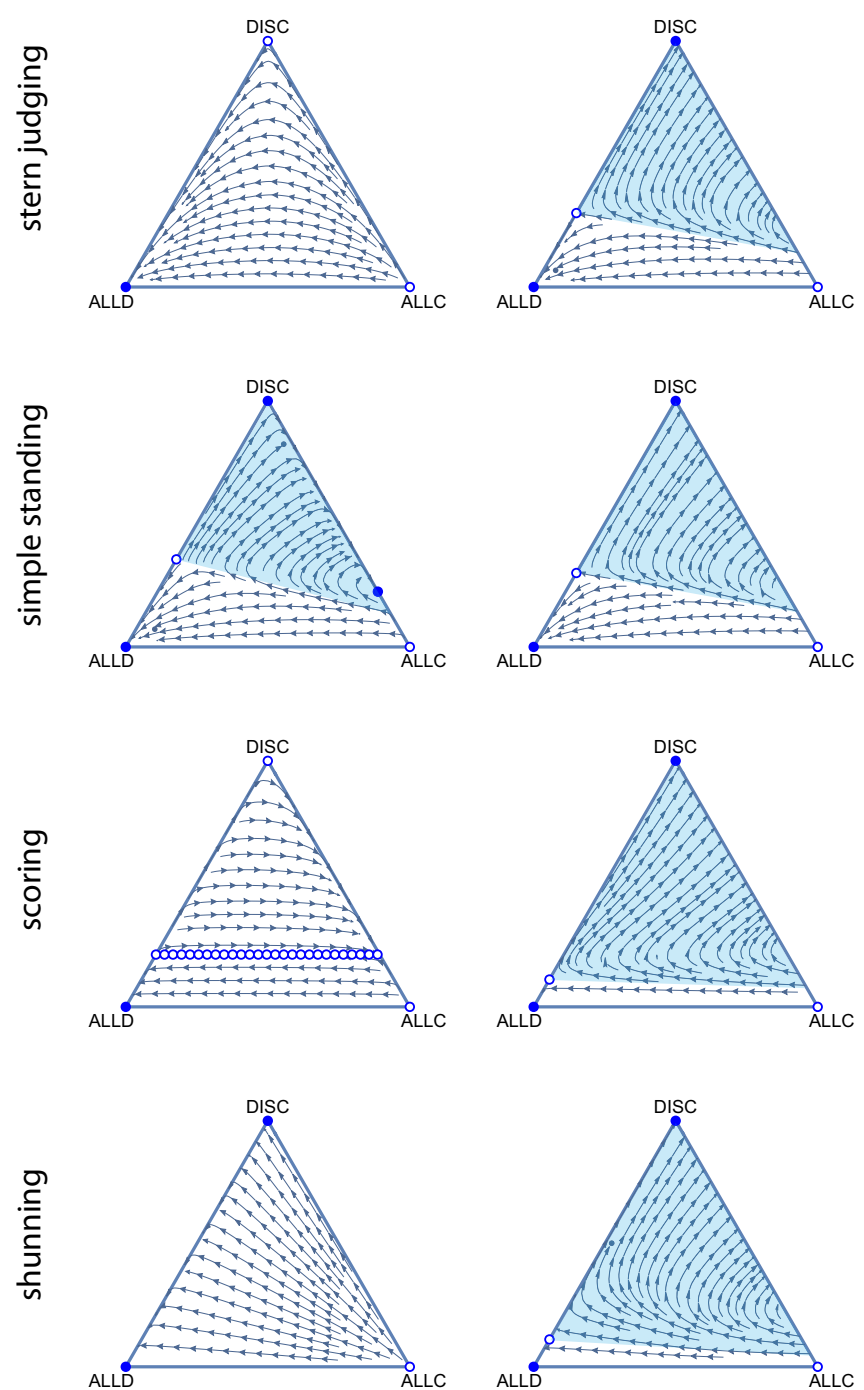

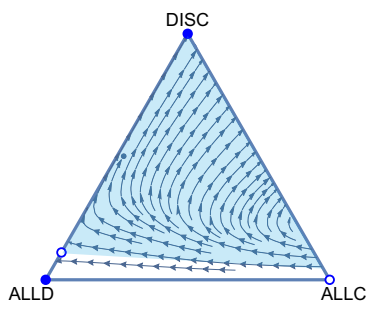

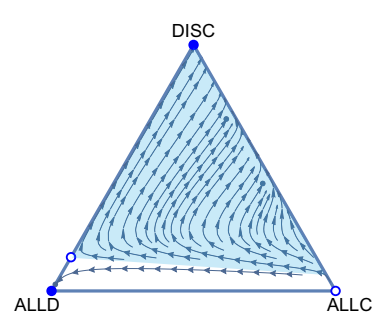

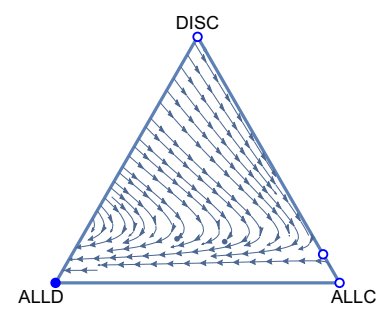

strict institution
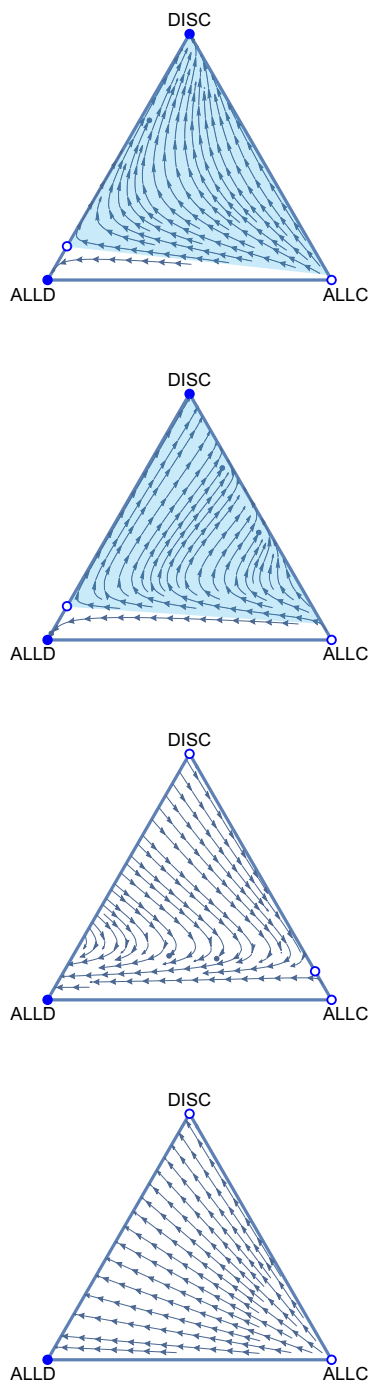

This has been corrected in both the PDF and HTML versions of the Article.

Published online: 21 July 2021

\begin{abstract}
(c) (1)
Open Access This article is licensed under a Creative Commons Attribution 4.0 International License, which permits use, sharing, adaptation, distribution and reproduction in any medium or format, as long as you give appropriate credit to the original author(s) and the source, provide a link to the Creative Commons license,

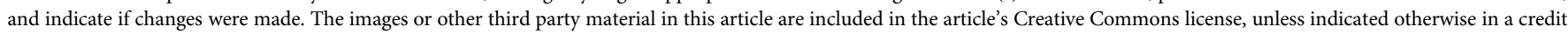
line to the material. If material is not included in the article's Creative Commons license and your intended use is not permitted by statutory regulation or exceeds the permitted use, you will need to obtain permission directly from the copyright holder. To view a copy of this license, visit http://creativecommons.org/licenses/by/4.0/.
\end{abstract}

(c) The Author(s) 2021 